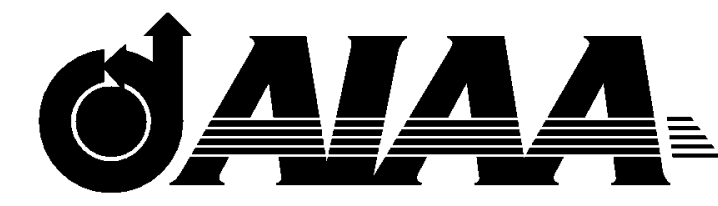

AIAA 2001-2834

Thermal Analysis and Design of Multi-layer Insulation for Re-entry Aerodynamic Heating

Kamran Daryabeigi

NASA Langley Reseacrh Center

Hampton, VA

35th AIAA Thermophysics Conference

$$
\begin{gathered}
\text { 11-14 June } 2001 \\
\text { Anaheim, CA }
\end{gathered}
$$

For permission to copy or to republish, contact the copyright owner named on the first page. For AIAA-held copyright, write to AIAA Permissions Department, 1801 Alexander Bell Drive, Suite 500, Reston, VA, 20191-4344. 


\title{
THERMAL ANALYSIS AND DESIGN OF MULTI-LAYER INSULATION FOR RE-ENTRY AERODYNAMIC HEATING
}

\author{
Kamran Daryabeigi ${ }^{*}$ \\ NASA Langley Research Center \\ Hampton, Virginia
}

\begin{abstract}
$\underline{\text { Abstract }}$
The combined radiation/conduction heat transfer in high-temperature multi-layer insulations was modeled using a finite volume numerical model. The numerical model was validated by comparison with steady-state effective thermal conductivity measurements, and by transient thermal tests simulating re-entry aerodynamic heating conditions. A design of experiments technique was used to investigate optimum design of multi-layer insulations for re-entry aerodynamic heating. It was found that use of $2 \mathrm{~mm}$ foil spacing and locating the foils near the hot boundary with the top foil $2 \mathrm{~mm}$ away from the hot boundary resulted in the most effective insulation design. A $76.2 \mathrm{~mm}$ thick multi-layer insulation using 1,4 , or 16 foils resulted in $2.9,7.2$, or 22.2 percent mass per unit area savings compared to a fibrous insulation sample at the same thickness, respectively.
\end{abstract}

\section{$\underline{\text { Introduction }}$}

A thermal protection system is used to maintain a reusable launch vehicle structural temperature within acceptable limits during re-entry aerodynamic heating. Metallic thermal protection systems have been proposed for insulating major portions of reusable launch vehicles. ${ }^{1}$ A metallic thermal protection system consists of a metallic shell panel fabricated from a hightemperature metallic alloy and mechanically attached to the vehicle structure; the shell is filled with lightweight, non-load-bearing insulation. The use of high temperature multi-layer insulation for use in this thermal protection system is investigated in the present study. The multi-layer insulation consists of thin ceramic/composite foils with high reflectance gold coatings separated by fibrous insulation spacers.

Heat transfer through a multi-layer insulation during re-entry into the atmosphere would involve combined modes of heat transfer: solid conduction through fibers, gas conduction and natural convection in spaces between fibers, and radiation interchange through participating media in the fibrous insulation spacers between reflective foils. However, natural convection was not considered in the present study. The objective of this investigation was to model the combined radiation/conduction heat transfer through multi-layer insulation with computational tools validated by experimental tests and to use the heat transfer model to design optimum multi-layer configurations.

\section{Previous Research}

A brief summary of the pertinent previous research in theoretical and experimental heat transfer in hightemperature multi-layer insulation is provided. Cunnington, et al., ${ }^{2}$ measured the effective thermal conductivity of seven multi-layer insulations up to $427^{\circ} \mathrm{C}$ and in vacuum $\left(5 \times 10^{-5} \mathrm{~mm}\right.$ of $\left.\mathrm{Hg}\right)$ in 1967 . They also performed theoretical modeling of the heat transfer using the optically thin approximation for the radiation interchange and compared results with experimental data. DeWitt, et al., ${ }^{3}$ extended the previous experimental work to $1000^{\circ} \mathrm{C}$ at a pressure of $1 \times 10^{-3} \mathrm{~mm}$ of $\mathrm{Hg}$ in 1968 and provided a theoretical formulation by neglecting gas conduction and modeling

Aerospace Engineer, Member AIAA

Copyright (C) 2001 by the American Institute of Aeronautics and Astronautics, Inc. No copyright is asserted in the United States under Title 17, U.S. Code. The U.S. Government has a royalty-free license to exercise all rights under the copyright claimed herein for Governmental Purposes. All other rights are reserved by the copyright owner. 
radiation using the optically thick approximation. Gallert and $\mathrm{Keller}^{4}$ discussed the feasibility of using a metallic thermal protection system with multi-layer insulation for hypersonic space transportation in 1989. Keller and his colleagues also provided various theoretical models of heat transfer in multi-layer insulation. ${ }^{5,6}$ They neglected solid conduction and used either the optically thick or the modified diffusion approximation for modeling the radiation transfer. Stauffer, et al., provided a theoretical formulation of multi-layer insulation using the optically thin approximation for the radiation transfer, and compared their predictions with previously published experimental results. The thermal design of multi-layer insulations has not been addressed in the previous research. Siegel modeled the combined solid conduction and radiation heat transfer in thin zirconia ceramic coatings with embedded thin metal foils for application to turbine engine combustors. ${ }^{8}$ He used the two-flux method for transient thermal analysis of a translucent wall with opaque radiation barriers. $\mathrm{He}$ used a Green's function to solve the set of equations governing the incident radiation using the two-flux approximation, and used a finite difference formulation for solving the governing conservation of energy equation.

In the present work the effective thermal conductivity of a multi-layer insulation was measured over an extended temperature and pressure range, 100 to $1000^{\circ} \mathrm{C}$ and $1 \times 10^{-4}$ to $760 \mathrm{~mm}$ of $\mathrm{Hg}$. Furthermore, transient tests simulating aerodynamic heating conditions were performed. The heat transfer through the insulation was modeled using combined solid and gaseous conduction and radiation. The radiation heat transfer was modeled using the two-flux approximation, which is valid over various optical thicknesses and is not limited to the optically thin or optically thick approximations. The governing conservation of energy equation was modeled using the finite volume technique, while the governing incident radiation equations were solved numerically using the finite difference approximation. The numerical heat transfer model was validated by comparison with both steadystate and transient measurements. The validated model was then used to design optimum multi-layer configurations for typical re-entry aerodynamic heating. The main contributions of the present work compared to previous research are: use of the two-flux radiation approximation for modeling radiation heat transfer in multi-layer insulations, validation of computational model with steady-state measurements over an extended range of pressures and temperatures, validation of the computational model with transient thermal tests simulating re-entry heating, and use of the validated computational model to design optimum multi-layer configurations for re-entry aerodynamic heating.

\section{Description of Multi-laver Sample}

The multi-layer sample investigated in this study for validation of the numerical heat transfer model consisted of reflective foils separated by layers of alumina fibrous insulation. It had five $304.8 \times 304.8 \times$ $0.0404 \mathrm{~mm}$ gold-coated foils with a density of 1343 $\mathrm{kg} / \mathrm{m}^{3}$. The fibrous insulation spacers were made of high purity polycrystalline alumina. The interior four fibrous spacers were $3.83 \mathrm{~mm}$ thick with a density of 24 $\mathrm{kg} / \mathrm{m}^{3}$, while the two outer fibrous spacers were 1.83 $\mathrm{mm}$ thick with the same density. The height of the insulation sample, combined foils and spacers, was $19.14 \mathrm{~mm}$ with a density of $37.1 \mathrm{~kg} / \mathrm{m}^{3}$. The insulation was wrapped in a $0.43 \mathrm{~mm}$ thick Nextel bag by the manufacturer. The density of the overall package was $77.1 \mathrm{~kg} / \mathrm{m}^{3}$.

\section{Thermal Testing Apparatus}

Both steady-state and transient tests were used for studying the thermal behavior of multi-layer insulations and for validating the computational heat transfer model that is used in the design study.

\section{Steady-State Thermal Testing Apparatus}

A thermal conductivity apparatus was developed to measure the steady-state effective thermal conductivity of insulations. The apparatus used in this study followed the general guidelines from ASTM standard $\mathrm{C} 201,{ }^{9}$ and a schematic of the apparatus is shown in Figure 1. The specimen to be tested was located between an Inconel septum plate and a water-cooled plate, both plates having dimensions of $304.8 \times 304.8$ $\mathrm{mm}$. The septum plate was heated by a ceramic radiant heater. The effective thermal conductivity of samples was measured with septum plate temperatures set at nominal temperatures between 100 and $1000^{\circ} \mathrm{C}$, with the water-cooled plate maintained around room temperature. The apparatus was located inside a vacuum chamber and the environmental pressure was varied between $1 \times 10^{-4}$ and $750 \mathrm{~mm}$ of $\mathrm{Hg}$. All the tests were conducted in a gaseous nitrogen environment. The water-cooled plate was instrumented with nine thin film heat flux gages and ten type $\mathrm{K}$ thermocouples. The septum plate was instrumented with 23 metalsheathed type $\mathrm{K}$ thermocouples. An uncertainty analysis was performed to obtain error estimates for the experimentally determined effective thermal 
conductivity. The overall uncertainty varied between 7.1 to 8.3 percent over the entire range of pressures and temperatures, with an average uncertainty of 7.5 percent. Details of the experimental apparatus and uncertainty analysis are provided by Daryabeigi. ${ }^{10}$ Measurements on a fumed silica board, Standard Reference Material (SRM) 1459 from the National Institute of Standard and Technology (NIST), at temperatures up to $300^{\circ} \mathrm{C}$ were within $5.5 \%$ of published data. ${ }^{10}$ The direction of the applied heating in the experimental setup was opposite the local gravity vector in order to eliminate natural convection as a mode of heat transfer.

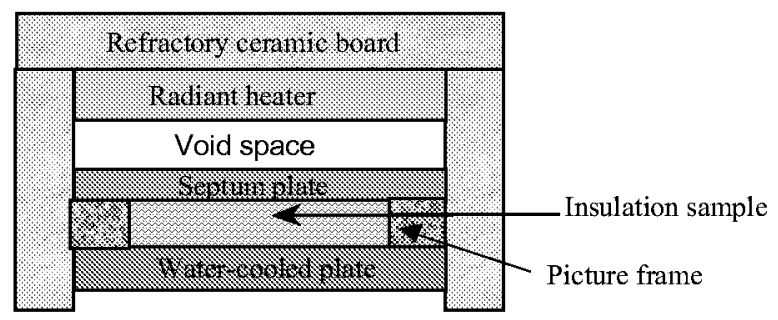

Figure 1. Schematic of thermal conductivity apparatus.

\section{Transient Thermal Testing Apparatus}

The steady-state thermal conductivity apparatus was modified to perform transient thermal testing of insulations simulating re-entry aerodynamic heating conditions. The heater was changed from a ceramic radiant heater to quartz lamp heating array in order to follow the transient re-entry heating profile.

Furthermore, a $3.2 \mathrm{~mm}$ thick aluminum plate was installed between the Inconel panel and the watercooled plate. A schematic of the transient thermal test apparatus is shown in Figure 2. The insulation package to be tested was located between the Inconel and aluminum plates. The Inconel panel served as the hot side solid boundary, while the aluminum plate represented the launch vehicle structure. The aluminum plate was placed $13.3 \mathrm{~mm}$ above a water-cooled plate with the space between them filled with alumina fibrous insulation with a density of $24.3 \mathrm{~kg} / \mathrm{m}^{3}$. The Inconel panel's temperature was controlled to simulate the transient radiative equilibrium temperatures during reentry. ${ }^{10}$ The water-cooled plate's temperature was maintained around room temperature. Therefore, two defined temperature boundary conditions were imposed on the experimental setup, which could also be specified in the numerical heat transfer model. The pressure in the vacuum chamber was varied in order to simulate re-entry conditions. All the tests were conducted in a gaseous nitrogen environment. Details of the experimental apparatus are provided by Daryabeigi. ${ }^{10}$ The comparison of predicted and measured temperature of the aluminum panel was used for validation purposes.
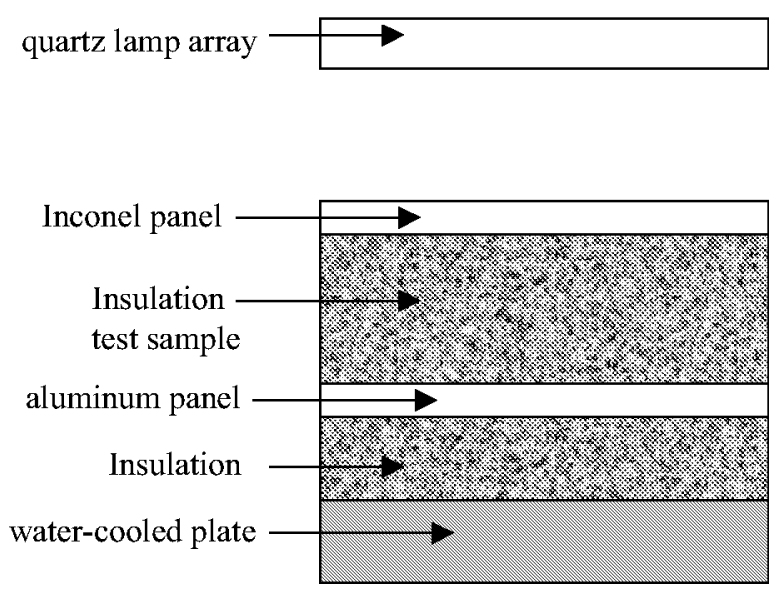

Figure 2. Schematic of transient thermal testing apparatus.

\section{Numerical Heat Transfer Model}

The governing conservation of energy equation for the problem of combined radiation and conduction in a radiation participating media with thickness L bounded by two solid surfaces at specified temperatures is given by: ${ }^{11}$

$$
\rho c \frac{\partial \mathrm{T}}{\partial \mathrm{t}}=\frac{\partial}{\partial \mathrm{x}}\left(\mathrm{k} \frac{\partial \mathrm{T}}{\partial \mathrm{x}}\right)-\frac{\partial \mathrm{q}_{\mathrm{r}}^{\prime \prime}}{\partial \mathrm{x}}
$$

subject to the following initial and boundary conditions:

$$
\begin{aligned}
& \mathrm{T}(\mathrm{x}, 0)=\mathrm{T}_{0} \\
& \mathrm{~T}(0, \mathrm{t})=\mathrm{T}_{1}(t) \\
& \mathrm{T}(\mathrm{L}, \mathrm{t})=\mathrm{T}_{2}(t)
\end{aligned}
$$

where $T$ is temperature, $\rho$ is density, $c$ is specific heat, $\mathbf{k}$ is thermal conductivity, $\mathrm{q}_{\mathrm{r}}{ }^{\prime \prime}$ is the radiant heat flux, $t$ is time, $x$ is the spatial coordinate through the insulation thickness, and $\mathrm{L}$ is the insulation thickness. The gradient of the radiant heat flux is given by:

$$
\frac{\partial \mathrm{q}_{\mathrm{r}}^{\prime \prime}}{\partial \mathrm{x}}=\beta(1-\omega)\left(\mathrm{G}-4 \sigma \mathrm{T}^{4}\right)
$$

where, $\beta$ is the extinction coefficient, $\omega$ is the albedo of scattering, $G$ is the incident radiation, and $\sigma$ is the Stefan-Boltzmann constant. Using the two flux 
approximation the radiant heat flux is related to incident radiation, $\mathrm{G}$, according to: ${ }^{12}$

$$
\mathrm{q}_{r}^{\prime \prime}=-\frac{1}{3 \beta} \frac{\partial \mathrm{G}}{\partial \mathrm{x}}
$$

The incident radiation in each fibrous spacer is obtained by solving the following second order differential equation:

$$
-\frac{1}{3 \beta^{2}(1-\omega)} \frac{\partial^{2} G}{\partial x^{2}}+G=4 \sigma T^{4}
$$

subject to the following boundary conditions at the bounding surfaces for the fibrous spacers, at two foils or a foil and a solid bounding surface:

$$
\begin{aligned}
& -\frac{2}{3 \beta\left(\frac{\varepsilon_{i}}{2-\varepsilon_{i}}\right)} \frac{\partial \mathrm{G}}{\partial \mathrm{x}}+\mathrm{G}=4 \sigma \mathrm{T}_{\mathrm{i}}^{4} \\
& \frac{2}{3 \beta\left(\frac{\varepsilon_{\mathrm{i}+1}}{2-\varepsilon_{\mathrm{i}+1}}\right)} \frac{\partial \mathrm{G}}{\partial \mathrm{x}}+\mathrm{G}=4 \sigma \mathrm{T}_{\mathrm{i}+1}^{4}
\end{aligned}
$$

where $\varepsilon$ is the emittance, and the subscripts $i$ and $i+1$ refer to the fibrous spacers' two bounding surfaces. Eq. (1) through (9) provide the governing equations and the most general form of the boundary conditions and initial conditions for the numerical heat transfer model. The assumptions used in the two-flux formulation consisted of: isotropic scattering, homogeneous and gray medium, diffuse emitting and reflecting surfaces.

Gas thermal conductivity does not vary with pressure but the exchange of heat from gas molecules to bounding solid surfaces is influenced by the environmental pressure in the rarefied and transition flow transport regimes. Thus, an effective gas thermal conductivity was defined as: ${ }^{13}$

$$
\mathrm{k}_{\mathrm{g}}=\frac{\mathrm{k}_{\mathrm{g}}^{*}}{1+2 \frac{2-\alpha}{\alpha}\left(\frac{2 \bar{\gamma}}{\bar{\gamma}+1}\right) \frac{1}{\operatorname{Pr}} \frac{\lambda_{\mathrm{m}}}{\mathrm{L}_{\mathrm{c}}}}
$$

where $\mathrm{k}_{\mathrm{g}}^{*}$ is the temperature-dependent gas thermal conductivity at atmospheric pressure, $\alpha$ is the thermal accommodation coefficient, $\bar{\gamma}$ is the gas specific heat ratio, $\operatorname{Pr}$ is the Prandtl number, $\lambda_{\mathrm{m}}$ is the molecular mean free path, and $L_{c}$ is the characteristic length. The gas molecular mean free path, $\lambda_{\mathrm{m}}$, is given by: ${ }^{14}$

$$
\lambda_{\mathrm{m}}=\frac{\mathrm{K}_{\mathrm{B}} \mathrm{T}}{\sqrt{2} \pi \mathrm{d}_{\mathrm{g}}^{2} \mathrm{P}}
$$

where $K_{B}$ is the Boltzmann constant, $T$ and $P$ are the gas temperature and pressure, and $\mathrm{d}_{\mathrm{g}}$ the gas collision diameter. The characteristic length, $\mathrm{L}_{\mathrm{c}}$, for gas conduction in fibers having a diameter $\mathrm{D}_{\mathrm{f}}$ is defined as: ${ }^{15}$

$$
\mathrm{L}_{\mathrm{c}}=\frac{\pi}{4} \frac{\mathrm{D}_{\mathrm{f}}}{\mathrm{f}}
$$

The solid fraction ratio, $\mathrm{f}$, is defined as the ratio of density of fibrous insulation to the density of fiber parent material.

Theoretical modeling of solid conduction through fibers and points of contact between them is difficult. Various empirical relations have been developed to model the solid conduction. The empirical model used in this study was:

$$
\mathbf{k}_{\mathrm{s}}=\mathrm{f}^{2} \mathbf{k}_{\mathrm{s}}^{*}
$$

where $\mathrm{k}_{\mathrm{s}}^{*}$ is the variation of the thermal conductivity of the fiber parent material with temperature. This model is based on the model proposed by Verschoor, et al. ${ }^{15}$ Different ways of modeling the interaction between solid and gas conduction have been used by various researchers. In the present study, it was assumed that solid and gas conduction were two thermal resistances in a parallel arrangement, leading to: ${ }^{16}$

$$
k=\mathrm{fk}_{\mathrm{s}} \dashv(1-\mathrm{f}) \mathrm{k}_{\mathrm{g}}
$$

The finite volume form of the conservation of energy equation, Eq. (1), was solved using an explicit time marching formulation. The foils were treated as lumped masses in the solution process. Constant temperature boundary conditions were used for specifying data from the steady-state thermal conductivity apparatus, while temporally varying boundary conditions were used for specifying the data from the transient heat transfer apparatus. The governing equation and boundary conditions for the incident radiation in each fibrous spacer given in Eq. (7) through (9) were solved using a finite difference technique. Uniform nodal spacing was used in each fibrous spacer region bounded by either two foils or a foil and a solid bounding surface, while the node spacing could vary between regions. 


\section{Validation of Numerical Model}

The specific extinction coefficient and albedo of scattering for the alumina fibrous insulation used in this study were determined in Ref. 10 (temperatures are in Kelvin):

$$
\begin{aligned}
& \mathrm{e}=41.92+0.0188 \mathrm{~T} \quad\left[\mathrm{~m}^{2} / \mathrm{kg}\right] \\
& \omega=0.939+5.564 \times 10^{-6} \mathrm{~T}
\end{aligned}
$$

These values were obtained by using a genetic algorithm search engine and a least squares minimization routine to estimate these parameters based on the difference between measured and predicted effective thermal conductivities of alumina fibrous insulation samples at a pressure of $10^{-4} \mathrm{~mm}$ of $\mathrm{Hg} .{ }^{10}$ The thermal accommodation coefficient for interchange between nitrogen gas and alumina fibers and the reflective foils was determined to be unity. ${ }^{10}$ The emittance of the gold-coated foils had been determined to have a constant value of 0.1 in the temperature range of 20 to $630^{\circ} \mathrm{C} .^{17}$ This value was used throughout the entire temperature range.

\section{$\underline{\text { Steady State Results }}$}

For validating the steady-state thermal conductivity measurements, the numerical solution was marched in time until steady state conditions were achieved. At steady state, the effective thermal conductivity was calculated from the Fourier's law of heat conduction using the calculated total steady-state heat flux (including contributions of both radiative and conductive heat fluxes) and the imposed temperature difference across the medium.

The comparison of predicted and measured effective thermal conductivities for the multi-layer sample at nominal pressures of $10^{-3}, 1$, and $750 \mathrm{~mm} \mathrm{Hg}$ is shown in Figure 3. The agreement between predictions and measurements at higher pressures and temperature differences larger than or equal to $400^{\circ} \mathrm{C}$ was within the 7.5 percent uncertainty range. The agreement was not as good at a pressure of $10^{-3} \mathrm{~mm}$ of $\mathrm{Hg}$. At this pressure the main mechanism for heat transfer was radiation, and therefore the overall numerical predictions were more sensitive to the emittance of gold foils. Percentage difference between predicted and measured effective thermal conductivities for all the data shown in the figure had an average of 9.8 percent with a standard deviation of 10.8 percent. Ignoring the data at $10^{-3} \mathrm{~mm}$ of $\mathrm{Hg}$, the difference had an average of 4.6 percent with a standard deviation of 6.5 percent. Therefore, the accuracy of the numerical heat transfer model was validated for steady-state performance of multi-layer insulation.

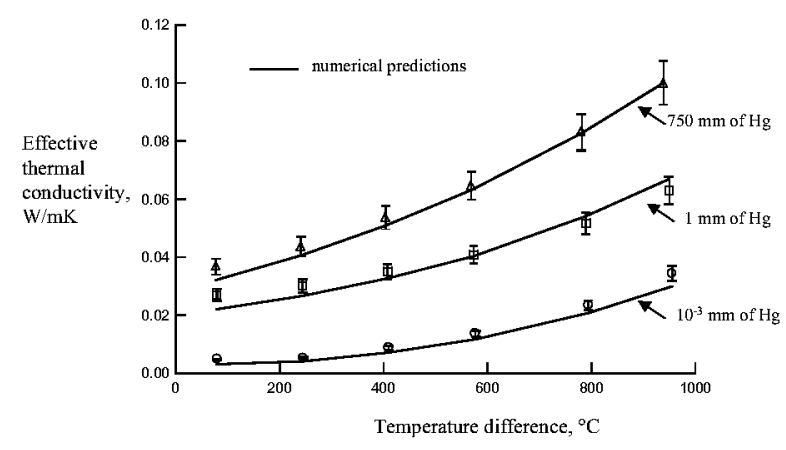

Figure 3. Comparison of predicted and measured effective thermal conductivity of multi-layer insulation at three environmental pressures.

\section{$\underline{\text { Transient Results }}$}

A transient thermal test was conducted with the multi-layer insulation sample. The measured temporal variations of the chamber pressure and of the Inconel panel temperature that could be achieved in simulating re-entry conditions are shown in Figures 4 and 5, along with the corresponding desired radiation equilibrium temperature and pressures for typical re-entry profiles that were used as control set points. Data are plotted versus elapsed time from the initiation of aerodynamic heating in atmospheric re-entry. The measured pressures followed the desired profile closely with the exception of elapsed time less than 300 seconds, where the actual measured pressures were higher than the desired values. The agreement between the measured and desired temperatures was good till 2300 seconds into the test, after which the measured temperatures deviated significantly from the re-entry profile. This was due to the fact that the high convective cooling rates in the atmosphere re-entry could not be duplicated with the test set-up in the vacuum chamber.

In simulating the test using the numerical model, the measured temporal variations of the Inconel panel and water-cooled plate temperature were used for the boundary conditions, and the measured pressure values were used for gas conduction calculations. The predicted and measured aluminum panel temperatures are shown in Figure 6. The difference between the predicted and measured temperatures had an average value of $-1.8^{\circ} \mathrm{C}$, with a standard deviation of $6.5^{\circ} \mathrm{C}$. The minimum and maximum differences were -11.2 and $13.2^{\circ} \mathrm{C}$, respectively. Overall, the close agreement between measured and predicted aluminum plate temperatures validated the numerical model for 
predicting the transient thermal performance of multilayer insulations subject to conditions similar to reentry aerodynamic heating conditions.

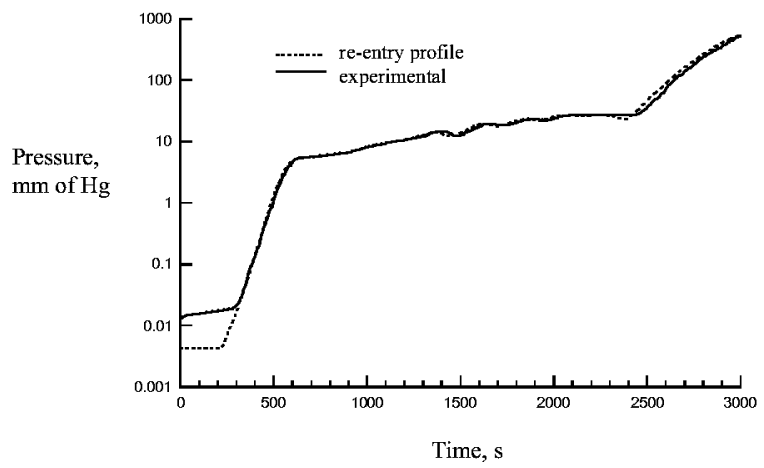

Figure 4. Comparison of measured pressure with typical re-entry pressure profile.

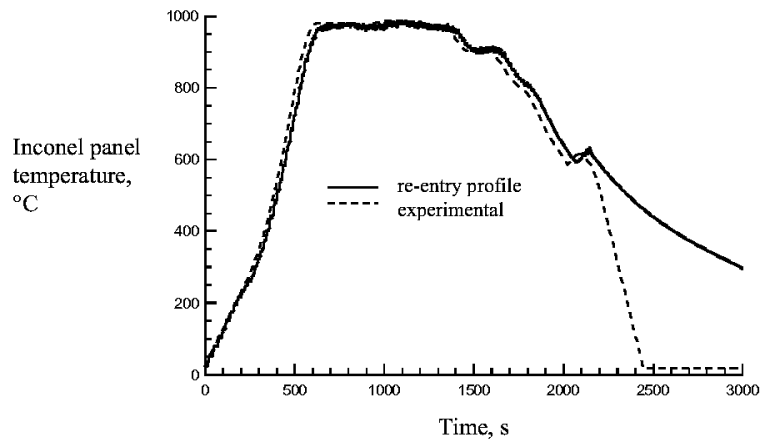

Figure 5. Comparison of measured temperature on the Inconel panel with typical re-entry radiation equilibrium temperature profile.

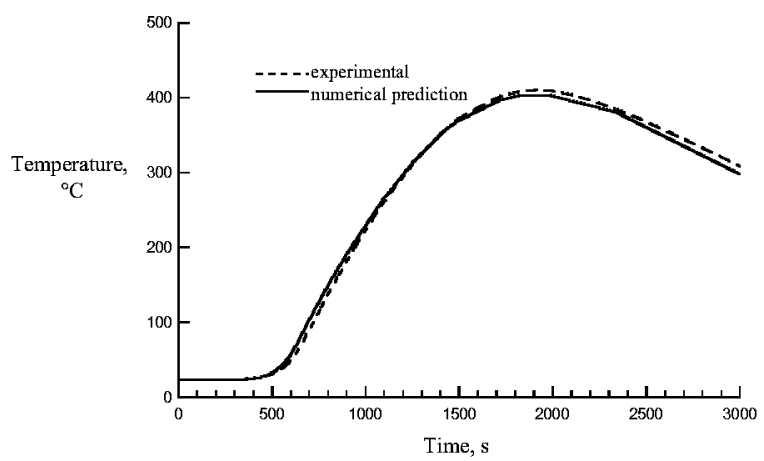

Figure 6. Comparison of predicted and measured aluminum panel temperatures for transient multi-layer insulation test.

\section{Design of Multi-Laver Insulation}

The overall goal in insulation design for a re-entry aerospace vehicle is to have the lowest-mass insulation while still protecting the vehicle's structure from exceeding its design temperature limit during the vehicle's re-entry into the atmosphere. Recent reusable launch vehicle designs are based on a metallic thermal protection system filled with fibrous insulation, therefore the multi-layer design performance was compared with fibrous insulation in a parametric study. A simplified thermal problem simulating re-entry aerodynamic heating conditions was used in this study. It was assumed that the insulation had a fixed thickness of $76.2 \mathrm{~mm}$, which is representative of a current metallic thermal protection system design, ${ }^{18}$ and was located between a $3.17 \mathrm{~mm}$ thick Inconel 718 panel and a $3.17 \mathrm{~mm}$ thick aluminum 2024 panel. It was assumed that the Inconel panel temperature and environmental pressure varied as the typical re-entry profile radiation equilibrium temperature and pressure shown in Figures 5 and 4 , respectively. The aluminum panel was assumed to be adiabatic, which is a standard assumption used for insulation design for space transportation vehicles, even though it has been shown to be very conservative. ${ }^{19}$ The insulation function was to prevent the aluminum panel temperature from exceeding a design limit of $177^{\circ} \mathrm{C}$. The numerical model described previously was utilized to model the heat transfer in pure fibrous insulation, and it was found that a fibrous insulation density of $60.48 \mathrm{~kg} / \mathrm{m}^{3}$ was needed in order not to exceed the aluminum panel's design temperature limit $\left(177^{\circ} \mathrm{C}\right)$. This density resulted in a mass per unit area (product of density and thickness) of $4.61 \mathrm{~kg} / \mathrm{m}^{2}$ for the fibrous insulation sample.

A design of experiments approach was used to identify the best thermal design of multilayer insulations. In design of experiments, a matrix of parameters, called design variables, are specified such that an "orthogonality" condition is satisfied. ${ }^{20}$ The values of the design variables in each row of the matrix specify an experiment, and the design variables are varied according to an orthogonal array layout. The columns of an orthogonal array are mutually "orthogonal", that is, for every pair of columns, all combinations of design variable levels occur and they occur an equal number of times. ${ }^{20}$ In the present discussion, an experiment refers to a numerical solution of the governing heat transfer equations for the thermal design problem described in the previous section using the specified design variables of: number of reflective foils, spacing between foils, and location of foils in the insulation. Each of the design variables was investigated at three levels: a high, low and a nominal 
estimate. For the number of foils, 2, 4, and 8 were chosen as the low, nominal and high estimates. Foil spacing design variables chosen were 2,5 and $8 \mathrm{~mm}$. Foil location was chosen as top, middle, or bottom. For the top design variable condition, the spacing between the top foil and the top of insulation was set equal to the specified foil spacing. For the bottom design variable condition, the spacing between the lowest foil and the bottom of insulation was set equal to the specified foil spacing. For the middle design variable condition, the foils were located symmetrically around the insulation's mid-plane. The orthogonal array used in this study was a three-level factor, L-9 orthogonal array ${ }^{20}$ and is shown in Table 1. A full factorial experiment for three parameters at three levels would have required 27 experiments. Use of orthogonal arrays reduced the number of experiments to nine. The experimental design approach using an orthogonal array assumes that the overall response of the system is obtained by linear superposition of the response of individual design variables with no interaction between the variables. ${ }^{20}$ Even though this assumption was not valid for the present design problem, the results illustrated significant trends in multi-layer design.

The transient thermal problem defined previously was solved numerically using the design variable settings for each of the nine experiments defined in Table 1. The thickness of the fibrous insulation spacers was adjusted so that the overall thickness of the foils and spacers was held constant at $76.2 \mathrm{~mm}$. For each experimental condition, the density of the spacers was chosen uniformly for all the spacers, and the governing heat transfer equations were solved numerically to obtain the maximum temperatures. To satisfy the constraint of limiting the aluminum panel's maximum temperature to $177^{\circ} \mathrm{C}$, a secant search of the required density value was performed. Convergence was achieved after two or three iterations. The effective mass per unit area of the nine configurations is listed in Table 1 . The relative mass per unit area savings for each configuration was determined by comparison with the mass per unit area of the pure fibrous insulation configuration $\left(4.61 \mathrm{~kg} / \mathrm{m}^{3}\right)$, and is also presented in the table. A negative number indicates that the mass of the experimental configuration was greater than the original fibrous insulation. All the multi-layer configurations with foils located at the bottom of the insulation package (close to the cold temperature boundary), performed worse than the pure fibrous insulation configuration irrespective of the number foils and foil spacing used. Not only did these designs not improve performance but foils at these locations could not even thermally compensate for the removal of equivalent mass of fibrous insulation. The multi-layer configurations with the foils located at the top, trial numbers 1,6 , and 8 , had the best performance. This result indicated that best performance could be expected with foils located near the hot boundary. The multi-layer configurations with the foils spaced in the middle of the insulation thickness (trials 2, 4, and 9) produced better results compared to fibrous insulation but did not match the performance of designs with foils located near the hot boundary. The best result for multi-layer configurations with middle foil locations was obtained with trial 9, resulting in mass saving of 2.2 percent. This configuration had eight foils with 8 $\mathrm{mm}$ spacing and was nearly a design with foils uniformly spaced throughout the insulation thickness (the top and bottom spacer regions were $9.9 \mathrm{~mm}$ thick while the seven interior spacers were $8 \mathrm{~mm}$ thick). But its performance was not as good as trial 8 with the same number of foils (eight), except the foils were located near the hot boundary with $5 \mathrm{~mm}$ foil spacing $(6.7$ percent mass saving). A statistical analysis called analysis of variance ${ }^{20}$ was used to investigate the affect of each of the design variables on the insulation mass, and it was found that the foil location was the dominant variable.

Using two foils at top with a foil spacing of $2 \mathrm{~mm}$ (trial 1) produced a mass saving of 3.8 percent. To further investigate foil spacing, an additional experiment was performed similar to trial 1, with two foils with a foil spacing of $5 \mathrm{~mm}$. The resulting mass saving was 2.9 percent, which was not as good as the mass saving of 3.8 percent obtained in trial 1 . This proved that using the lowest possible foil spacing ( 2 $\mathrm{mm}$ ) when foils are located near the hot boundary is the optimum multi-layer design philosophy.

\begin{tabular}{|c|c|c|c|c|c|}
\hline $\begin{array}{c}\text { trial } \\
\text { number }\end{array}$ & $\begin{array}{c}\text { number } \\
\text { of foils }\end{array}$ & $\begin{array}{c}\text { foil } \\
\text { spacing } \\
\mathbf{( m m )}\end{array}$ & $\begin{array}{c}\text { foil } \\
\text { location }\end{array}$ & $\begin{array}{c}\text { mass/ } \\
\text { area } \\
\mathbf{( k g / \mathbf { m } ^ { 3 } )}\end{array}$ & $\begin{array}{c}\text { mass/ } \\
\text { area } \\
\text { saving } \\
\mathbf{( \% )}\end{array}$ \\
\hline 1 & 2 & 2 & top & 4.43 & 3.8 \\
\hline 2 & 2 & 5 & middle & 4.60 & 0.3 \\
\hline 3 & 2 & 8 & bottom & 4.61 & -0.1 \\
\hline 4 & 4 & 2 & middle & 4.56 & 0.9 \\
\hline 5 & 4 & 5 & bottom & 4.64 & -0.7 \\
\hline 6 & 4 & 8 & top & 4.50 & 2.4 \\
\hline 7 & 8 & 2 & bottom & 4.70 & -1.9 \\
\hline 8 & 8 & 5 & top & 4.30 & 6.7 \\
\hline 9 & 8 & 8 & middle & 4.51 & 2.2 \\
\hline
\end{tabular}

Table 1. Results of design of experiment analysis (a negative number indicates mass gain). 
These results are consistent with basic heat transfer principles. The reflective foils' main function is to provide high thermal resistance to radiation heat transfer in the insulation due to their high reflectance. The resistance value is inversely proportional to the optical thickness of the fibrous spacers between the foils. If the fibrous spacer is optically thick, the reflectance of the foils will not have any appreciable effect on the overall radiation heat transfer. ${ }^{11}$ The fibrous spacer should have a low value of optical thickness so that the high reflectance of its bounding surfaces (foils) can influence the radiation heat transfer. The optical thickness of the fibrous spacer, $\tau_{0}$, is the product of the spacer thickness, $L^{\prime}$, density, $\rho$, and specific extinction coefficient, e, according to: ${ }^{21}$

$$
\tau_{0}=\mathrm{eL}^{\prime} \rho
$$

Since the specific extinction coefficient is an intrinsic property of the spacer material, spacer thickness and density are the only variables that can affect the optical thickness. For a fixed spacer density, lowering the spacer thickness results in a lower optical thickness, and a higher thermal resistance to radiation heat transfer. Based on the author's experience in assembling multi-layer insulations, a foil spacing of 2 $\mathrm{mm}$ was the lowest reasonable spacer thickness that could be achieved on a consistent basis. Furthermore, since radiation is the dominant mode of heat transfer near the hot boundary, ${ }^{10}$ placing the foils in this region will impede radiation heat transfer more effectively.

Using the optimum design philosophy, the influence of the number of foils was investigated. Results were obtained with $1,2,4,8$, and 16 foils, and are presented in Table 2. With 16 foils, the bottom spacer is $43.5 \mathrm{~mm}$ thick, so all the foils are located in the upper half of the insulation. One foil resulted in a mass saving of $2.9 \%$. The mass saving increased with increasing number of foils, reaching $22.2 \%$ for 16 foils. The percent saving per foil is also listed in the table. The largest percent saving was achieved with one foil (2.9 percent per foil), and the percent saving per foil decreased with increasing foil number. The cost of the gold-coated reflective foils is extremely high compared to the cost of alumina fibrous insulation. Therefore, the present approach can be used in future studies to provide insights regarding the costs and benefits of multi-layer insulations.

\begin{tabular}{|c|c|c|}
\hline $\begin{array}{c}\text { number } \\
\text { of foils }\end{array}$ & $\begin{array}{c}\text { mass/area } \\
\text { saving (\%) }\end{array}$ & $\begin{array}{c}\text { Mass/area } \\
\text { saving per foil } \\
\text { (\%/foil) }\end{array}$ \\
\hline 1 & 2.9 & 2.9 \\
\hline 2 & 3.8 & 1.9 \\
\hline 4 & 7.2 & 1.8 \\
\hline 8 & 12.6 & 1.6 \\
\hline 16 & 22.2 & 1.4 \\
\hline
\end{tabular}

Table 2. Mass savings for optimized multi-layer insulation configurations compared to fibrous insulation.

\section{Concluding Remarks}

A numerical model was developed for modeling combined radiation/conduction heat transfer in hightemperature multi-layer insulations. The numerical model was validated by comparison with steady-state effective thermal conductivity measurements, and by transient thermal tests simulating re-entry aerodynamic heating conditions. A design of experiments approach was used to determine the optimum design rules for multi-layer insulations subjected to re-entry aerodynamic heating. It was found that use of $2 \mathrm{~mm}$ foil spacing and locating the foils near the hot boundary with the top foil $2 \mathrm{~mm}$ away from the hot boundary resulted in the most effective insulation design. For the specific conditions investigated, a $76.2 \mathrm{~mm}$ thick multilayer insulation using 1,4 , or 16 foils resulted in 2.9 , 7.2 , or 22.2 percent mass per unit area savings compared to a fibrous insulation sample at the same thickness, respectively.

\section{Acknowledgements}

The author would like to thank the following NASA Langley Research Center employees for their invaluable support: Wayne D. Geouge for fabrication and instrumentation of the test apparatus, and Jeffrey $R$. Knutson for providing temperature and pressure controls for the tests. The author would also like to express his gratitude to Ms. Karin Handrick, MAN Technology AG, and Mr. Steve D. Miller, S.D. Miller \& Associates, for providing various multi-layer insulation samples. 


\section{$\underline{\text { References }}$}

1. Blosser, M.L., Martin, C.J., Daryabeigi, K., and Poteet, C.C., "Reusable Metallic Thermal Protection System Development," Presented at the Third European Workshop on Thermal Protection Systems, ESTEC, The Netherlands, 1998.

2. Cunnington, G.R., Zierman, C.A., Funai, A.I., and Lindahn, A., "Performance of Multilayer Insulation Systems for Temperatures to 700K," NASA CR-907, October 1967.

3. DeWitt, W.D., Gibbon, R.L., and Reid, R.L., "Multi-foil Type Thermal Insulation," Proceedings of Intersociety Energy Conversion Engineering Conference (IECEC), 1968, pp. 263-271.

4. Gallert, H., and Keller, K., "Metallic Thermal Protection Concept for Hypersonic Vehicles," Journal of Aircraft, Vol. 28, No. 6, June 1991, pp. 410-416.

5. Keller, K., Blumenberg, J., and Tomsik, J., "Fibre Orientation and the Conduction of Heat By a Gas Enclosed in Ceramic Layers," Z. Flugwiss. Weltraumforsch., Vol. 12, 1988, pp. 258-260.

6. Keller, K., Hoffmann, M., Zorner, W., and Blumenberg, J., "Application of High Temperature Multilayer Insulations," Acta Astronautica, Vol. 26, No. 6, 1992, pp. 451-458.

7. Stauffer, T., Jog, M., and Ayyaswamy, P., "The Effective Thermal Conductivity of Multi Foil Insulation as a Function of Temperature and Pressure," AIAA Paper 92-2939, AIAA $27^{\text {th }}$ Thermophysics Conference, Nashville, Tennessee, July 1992.

8. Siegel, R., "Transient Thermal Analysis for Heating a Translucent Wall with Opaque Radiation Barriers," Journal of Thermophysics and Heat Transfer, Vol. 13, No. 3, July-September 1999, pp. 277-284.

9. ASTM Standard C 201: "Standard Test Method for Thermal Conductivity of Refractories," 1996 Annual Book of ASTM Standards, Vol. 15.01, Refractories, Carbon and Graphite Products, Activated Carbon Advanced Ceramics, 1996.

10. Daryabeigi, K., " Design of High temperature Multi-layer Insulation," Ph.D. Dissertation, University Of Virginia, May 2000.
11. Sparrow, E.M., and Cess, R.D., Radiation Heat Transfer, Augmented Edition, 1978, McGraw- Hill Book Company.

12. Ozisik, M.N., Radiative Transfer and Interactions with Conduction and Convection, 1973, John Wiley \& Sons, Inc.

13. Gebhart, B., Heat Conduction and Mass Diffusion, 1993, McGraw- Hill Book Company.

14. Williams, S.D, and Curry, D.M., "Predictions of Rigid Silica Based Insulation Conductivity Using Morphological Data," Presented at the $29^{\text {th }}$ National Heat Transfer Conference, Atlanta, Georgia, August 1993.

15. Verschoor, J.D., Greebler, P., and Manville, N.J., "Heat Transfer by Gas Conduction and Radiation in Fibrous Insulation," Journal of Heat Transfer, Vol. 74, August1952, pp. 961-968.

16. Schnider, P.J., "Conduction," Section 3, Handbook of Heat Transfer, Edited by W.M. Rohsenow and J.P. Hartnet, 1973, McGraw- Hill Book Company.

17. Handrick, K., Muehlratzer, A., and Weber, K.H., "Fiber Reinforced Ceramic Foils for a Lightweight Thermal Insulation," Proceedings of the $6^{\text {th }}$ European Conference on Composite Materials, September 20-24, 1993, Bordeaux, France, pp. 759-766.

18. Blosser, M., "Advanced Metallic Thermal Protection Systems for Reusable Launch Vehicles," Ph.D. Dissertation, University Of Virginia, May 2000.

19. Ko, W.L., Quinn, R.D., and Gong, L., "FiniteElement Reentry Heat-transfer Analysis of Space Shuttle Orbiter," NASA TP 2657, December 1986.

20. Phadke, M.S., Quality Engineering Using Robust Design, 1989, Prentice Hall.

21. Siegel, R., and Howell, J.R., Thermal Radiation Heat Transfer, $2^{\text {nd }}$ Edition, 1981, McGraw- Hill Book Company. 